\title{
Stress drop variation of deep-focus earthquakes based on empirical Green's functions
}

\author{
Meichen Liu ${ }^{1}$, Yihe Huang ${ }^{1}$, and Jeroen Ritsema ${ }^{1}$ \\ ${ }^{1}$ Department of Earth and Environmental Sciences, University of Michigan, Ann Arbor, MI 48109, USA
}

\section{Key Points:}

- Empirical Green's functions are applied to analyze stress drops of deep-focus earthquakes

- One standard deviation range are 3.5-369.8 MPa for $\mathrm{P}$ waves and 8.2-328.9 $\mathrm{MPa}$ for $\mathrm{S}$ waves

- The median stress drops suggest that fault shear stress is an order of magnitude higher in the mantle than in the crust

Corresponding author: Meichen Liu, meichenl@umich.edu 


\begin{abstract}
We analyze source characteristics of global, deep-focus $(>350 \mathrm{~km})$ earthquakes with moment magnitudes ( $\mathrm{Mw}$ ) larger than 6.0-8.2 using teleseismic P-wave and S-wave spectra and an empirical Green's functions approach. We estimate the corner frequency assuming Brune's source model and calculate stress drops assuming a circular crack model. Based on $\mathrm{P}$-wave and S-wave spectra, the one-standard deviation ranges are 3.5-369.8 $\mathrm{MPa}$ and $8.2-328.9 \mathrm{MPa}$, respectively. Based on the $\mathrm{P}$-wave analysis, the median of our stress-drop estimates is about a factor of 10 higher than the median stress drop of shallow earthquakes with the same magnitude estimated by Allmann and Shearer (2009). This suggests that, on average, the shear stress of deep faults in the mantle transition zone is an order of magnitude higher than the shear stress of faults in the crust. The wide range of stress drops implies coexistence of multiple physical mechanisms.
\end{abstract}

\title{
Plain Language Summary
}

The change of shear stress (i.e., stress drop) during an earthquake is thought to be larger for deeper earthquakes than shallow earthquakes because of higher overburden pressure. However, the observational evidence for stress drop dependence on depth is still inconclusive. We estimate stress drops of earthquakes deeper than $400 \mathrm{~km}$ from recorded ground motion spectra. We find that the median stress drop of deep earthquakes is about one order of magnitude higher than the stress drop of shallow $(<50 \mathrm{~km})$ earthquakes. This implies that the shear stress of deep faults is moderately higher than of faults in the crust. The wide range of our stress drop estimates suggests that various mechanisms producing deep earthquakes coexist.

\section{Introduction}

High temperatures and stresses in excess of $1000 \mathrm{MPa}$ should inhibit brittle failure at depths larger than $50 \mathrm{~km}$. However, approximately $25 \%$ of earthquakes occur at these large depths (Frohlich, 1989) and they have nearly double-couple mechanisms. This suggests that deep earthquakes involve shear faulting on a planar surface similar to crustal earthquakes.

Previous studies have proposed two physical mechanisms of deep-focus ( $>350 \mathrm{~km})$ earthquakes as shear failures: (1) metastable phase transformation (e.g., Kirby, 1987; H. Green \& Burnley, 1989; H. W. Green \& Houston, 1995) and (2) shear-induced melting (e.g., Aki, 1972; Kanamori et al., 1998; Karato et al., 2001). In the first mechanism, small lenticular cracks nucleate as a result of the volume decrease during the olivine-tospinel phase transformation and form macroscopic faults. In the second mechanism, frictional melts on pre-existing faults lubricate the fault plane, reduce dynamic shear strength, and facilitate earthquake rupture. Once triggered, a shear instability evolves into a cascading failure (Chen \& Wen, 2015), which may propagate at a super-shear rupture velocity (Zhan et al., 2015).

Previous studies of deep-focus earthquakes produced inconsistent results. For example, Poli and Prieto (2016) determined that the radiation efficiencies of intermediatedepth (30-350 km) and deep-focus earthquakes are different. Persh and Houston (2004) related distinct changes of aftershock productivity at depths of $300 \mathrm{~km}$ and $550 \mathrm{~km}$ to different metastable phase transformations. Both studies suggest a change of the rupture mechanism with depth. In contrast, Campus and Das (2000) did not observe an obvious difference in the spectral properties and the source time functions of intermediatedepth and deep-focus events. The global invariance of strain drops with depth based on the analysis of source time functions (Vallée, 2013) indicates that one single mechanism could be responsible for all earthquakes. 


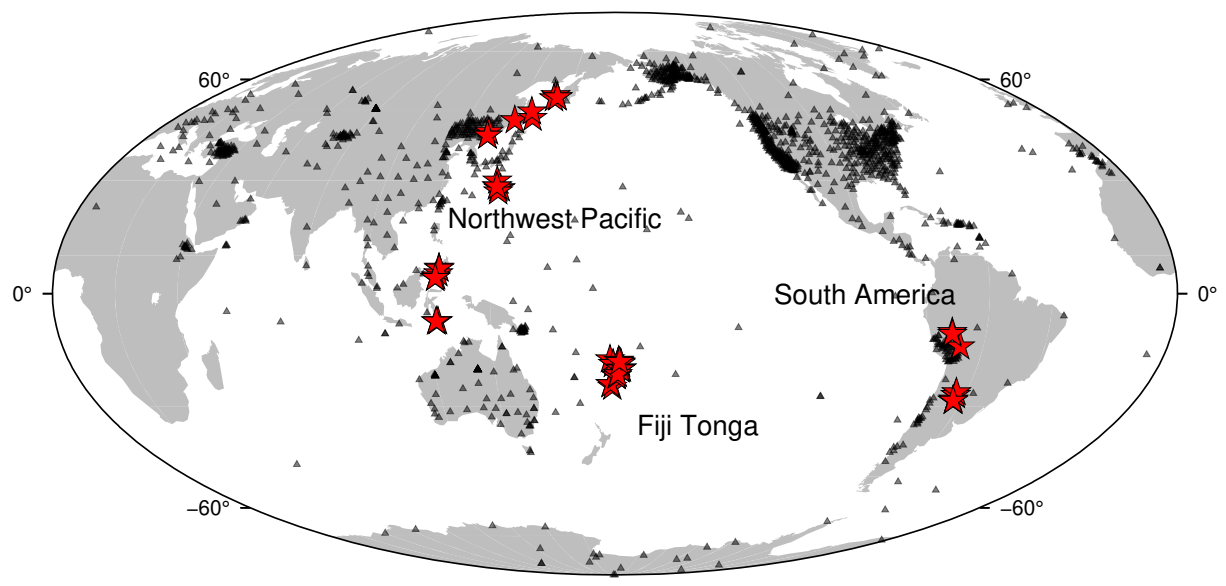

Figure 1. Global distribution of master events (stars; see also Table 1) and stations (triangles) used in this study

In this paper we evaluate whether stress drops of shallow and deep-focus earthquakes are significantly different. Stress drop is the difference between shear stresses along the fault before and after an earthquake. It is a fundamental parameter for understanding the physics of the rupture process (Kanamori \& Brodsky, 2004). If the shear-failure processes are similar, deep-focus earthquakes should exhibit higher stress drops than shallow earthquakes due to larger fault shear stresses.

Early studies by Aki (1972) and (Kanamori \& Anderson, 1975) suggested stress drops of deep earthquakes are an order of magnitude larger than the range of 1-10 MPa of crustal earthquakes. However, recent analyses of larger data sets indicate that stress drops of crustal earthquakes can vary significantly and that stress drops of shallow and deep earthquakes are similar. For example, the stress drops of $95 \%$ of global crustal earthquakes studied by Allmann and Shearer (2009) using globally averaged empirical Green's functions (eGfs) are between 0.22 and $66 \mathrm{MPa}$. Poli and Prieto (2016) found the stress drops of $95 \%$ of earthquakes at depths of $400-700 \mathrm{~km}$ are $3.6-49.2 \mathrm{MPa}$ from the analysis of source time functions.

To measure stress drops of deep-focus earthquakes (Figure 1), we analyze teleseismic P-wave and S-wave spectra using the spectral ratio approach based on empirical Green's functions (eGfs) (Huang et al., 2016). We compare our stress drops of deep-focus earthquakes to those of shallow earthquakes estimated by Allmann and Shearer (2009), the only published stress drop study for global shallow earthquakes based on eGfs.

\section{Methods}

\subsection{Corner Frequency and Stress Drop Estimates}

The spectrum of a teleseismic $\mathrm{P}$ wave or $\mathrm{S}$ wave is $u(f)=S(f) P(f) R(f)$, where the factors $S, P$, and $R$ are the source, path and receiver-side contributions, respectively. We can determine the ratio of the source spectra $S_{M}(f)$ and $S_{e G f}(f)$ by dividing the $\mathrm{P}$-wave or S-wave spectra $u_{M}$ for a large earthquake (i.e., the master event) by the spectra $u_{e G f}$ for a smaller nearby earthquake (i.e., the eGf) recorded at the same station (Aki, 1967; Mueller, 1985; Frankel \& Wennerberg, 1989; Imanishi \& Ellsworth, 2006; Abercrombie, 2015). For the Brune source model (Brune, 1970) $S\left(f, f_{c}\right)=M_{0} /\left(1+\left(f / f_{c}\right)^{2}\right)$, where $M_{0}$ is the seismic moment and $f_{c}$ is the corner frequency, $S_{M}(f) / S_{e G f}(f)$ has a 
sigmoidal shape with a high plateau at low frequencies determined by the ratio of the seismic moments and a spectral fall-off between the corner frequencies of the master event and the eGf. From here on, we denote the corner frequencies of the master event and the and the eGf as $f_{M}$ and $f_{e G f}$.

Abercrombie (2015) recommended to select eGfs that are located within one-source dimension of the master event in order to cancel out $P(f)$ and $R(f)$. We therefore choose eGfs at hypocentral distances within 100,300 , and $500 \mathrm{~km}$ from master events with moment magnitudes in the range of 6-7, 7-8, and 8-9 (only two events), respectively. Using a distance threshold of $300 \mathrm{~km}$ for the two Mw8 events does not significantly change our stress drop estimates (Figure S1). We require the eGfs to have magnitudes that are at least 0.5 lower to ensure that $f_{M}$ and $f_{e G f}$ are distinguishable. We allow eGfs to have different focal mechanisms because the source-radiation effects are small when spectra are averaged from stations over a wide range of source azimuths (Calderoni et al., 2015; Ross \& Ben-Zion, 2016).

The source radius $r$ of a master earthquake is related to $f_{c}$ by $r=k v / f_{c}$, where $v$ is the $\mathrm{S}$-wave velocity varying with depth. We assume a circular shear crack model, so the stress drop $\Delta \tau$ is related to $r$ as $\Delta \tau=7 M_{0} / 16 r^{3}$ (Eshelby, 1957). Here we assume that the rupture velocity is constant and $90 \%$ of the shear-wave velocity, and choose $k_{P}=0.32$ for $\mathrm{P}$ wave and $k_{S}=0.21$ for $\mathrm{S}$ wave following Madariaga (1976) to facilitate the comparison with Allmann and Shearer (2009). It is possible that the stress drop variability observed in this study stems from rupture velocity variation. Both stress drop and rupture velocity determine the corner frequency and the rupture velocities of individual earthquakes are poorly constrained (Houston, 2015; Chounet et al., 2018). This is the case for deep-focus as well as shallow earthquakes (Allmann \& Shearer, 2009; Vallée, 2013). Houston (2015) has shown that the majority of deep-focus earthquakes have rupture velocities that range between $50 \%$ and $90 \%$ of the shear-wave velocity. If we assume that the rupture velocity is $50 \%$ of the shear-wave velocity, $\Delta \tau$ estimated from $\mathrm{P}$-wave and S-wave spectra would increase by a factor of $\sim 2.5$ and $\sim 1.7$, respectively, based on estimates of $k_{P}$ and $k_{S}$ by Sato and Hirasawa (1973) and Kaneko and Shearer (2014). The increase is small compared to the differences in the stress drops of deep-focus and shallow earthquakes (Figure S2).

\subsection{P-wave and S-wave Spectral Ratio Analysis}

We analyze P-wave and S-wave spectra using vertical-component and transversecomponent waveforms recorded at epicentral distances smaller than 85 degrees. We apply the multi-window method (Imanishi \& Ellsworth, 2006; Huang et al., 2016) to stack spectra for five windows that are each $40 \mathrm{~s}$ long and overlap by $20 \mathrm{~s}$. The first window begins 5 s before the theoretical (i.e., PREM; Dziewonski \& Anderson, 1981) arrival time. The windows include coda waves with important source information (Aki \& Chouet, 1975). We find that stacked spectra for window lengths from to 120 seconds are not significantly different.

We use data with a signal-to-noise ratio (SNR) higher than 2 in each of the frequency bands $0.025-0.1 \mathrm{~Hz}, 0.1-0.4 \mathrm{~Hz}, 0.4-0.9 \mathrm{~Hz}$, and $0.9-2.0 \mathrm{~Hz}$. The SNR is defined as the ratio of the $\mathrm{P}$ wave or $\mathrm{S}$ wave amplitude and the average amplitude of the noise in the 40 -s long window before the $\mathrm{P}$ wave and $\mathrm{S}$ wave onsets. We average the spectral ratios from at least three stations. The corner frequency $f_{M}$ may be underestimated when it is within a factor of 1.5 (Ruhl et al., 2017) to 3.0 (Abercrombie, 2015) of the maximum signal frequency. It is difficult to resolve $f_{M}$ if the low-frequency plateau is not distinguishable from the high-frequency spectral fall-off but we can estimate $f_{M}$ reliably if it has a value between 0.05 and $0.67 \mathrm{~Hz}$. Due to the limited bandwidth of our data, $f_{e G f}$ is poorly resolved for most eGfs. In addition, we require that the magnitude difference between the master events and the eGfs, determined by moment ratios, is within 0.5 units 
of the magnitude difference in the ANSS Comprehensive Earthquake Catalog (Figure S3).

After resampling the $\mathrm{P}$-wave and $\mathrm{S}$-wave spectra evenly in the log domain, we estimate $f_{M}$ of the master event and its uncertainty by fitting the average spectral ratio to the theoretical curve in the $0.025-2.0 \mathrm{~Hz}$ frequency range using two approaches. The first approach is based on a grid search. We compute the least-squares misfit between the stacked and the theoretical spectral ratios (assuming the Brune model) as a function of $f_{M}$ and $f_{e G f}$ for a fixed moment ratio determined by the spectral ratio at the lowest frequencies. In the second approach, we estimate $f_{M}$ using the Trust-Region-Reflective least squares algorithm by (Branch et al., 1999). We bootstrap the residuals between the observed and the best-fit spectral ratios at each frequency and create a synthetic spectral ratio by adding the bootstrapping residuals to the best-fit spectral ratios. We repeat this process 1,000 times to obtain a Gaussian distribution of $f_{M}$ values for 1,000 synthetic spectral ratios. The $95 \%$ confidence interval is similar to the range of resolved values along the 1.01 misfit contour (defining the minimum misfit to be 1 ). We retain an estimate of $f_{M}$ only when its distribution has a two-standard deviation smaller than 0.05 in the log domain, which is within 0.89-1.12 times the best-fit corner frequency. We likely underestimate the uncertainties in the estimate of the corner frequency because we have not considered the effects of imperfect cancellation of propagation path and site effects in our analysis.

Figure 2 illustrates our analysis for the 2013 Sea of Okhotsk earthquake (Event 5 in Table S1). Figure 2a shows station-averaged P-wave spectral ratios for three eGfs $(2009 / 12 / 01$, Mw6.3; 2013/10/01, Mw6.7; 2013/05/24, Mw6.7). The estimates of $f_{M}$ range from 0.075 to $0.15 \mathrm{~Hz}$. Three panels in Figure 2b show that the spectra of the three eGfs can be matched by theoretical ratios within a misfit of 1.01 when estimates of $f_{M}$ of Event 5 vary between $0.11-0.13 \mathrm{~Hz}$ for eGf $1,0.074-0.08 \mathrm{~Hz}$ for eGf 2 , and $0.14-0.16 \mathrm{~Hz}$ for eGf 3 . The bootstrapping results in Figure 2c indicate that $f_{M}$ is $0.12 \mathrm{~Hz}, 0.08 \mathrm{~Hz}$, and $0.15 \mathrm{~Hz}$ for eGfs 1, 2, and 3, respectively. In Table S1, we report that Event 5 has a corner frequency $f_{M}=0.11 \pm 0.01 \mathrm{~Hz}$ based on this analysis.

\section{Estimates of Corner Frequencies and Stress Drop}

Our analysis is based on global waveform data of earthquakes from 2000 to 2018 listed in the ANSS Comprehensive Earthquake Catalog with focal depths larger than 400 $\mathrm{km}$ and moment magnitudes higher than 5.5. Using 2,860 P-wave recordings of 28 earthquakes and 2,296 S-wave recordings of 29 earthquakes, we measure 116 and 95 corner frequencies from analyses of $\mathrm{P}$-wave and S-wave spectra that meet the quality control criteria. We show observed and modeled spectral ratios in Figure S4 and document source parameters in Table S1.

Figures $3 \mathrm{a}$ and $3 \mathrm{~b}$ show estimates of $f_{M}$ from the analysis of $\mathrm{P}$ waves and $\mathrm{S}$ waves, respectively. The $\mathrm{P}$-wave corner frequencies vary from 0.05 to $0.67 \mathrm{~Hz}$, which is the same as the resolvable frequency range, whereas the $\mathrm{S}$-wave corner frequencies vary from 0.06 to $0.26 \mathrm{~Hz}$. In Supplementary Figure S5 we show that the estimates of $f_{M}$ are similar for the Boatwright model (Boatwright, 1980), which predicts a steeper decrease of the source spectra at frequencies higher than $f_{M} . f_{M}$ varies by a factor of 6 (for S waves) to 10 (for $\mathrm{P}$ waves) but a dependence on magnitude is not obvious. For example, $f_{M}$ for events 41 and 53 (see Supplementary Figure S4) are similar although the event magnitudes are different by about 1 . The magnitudes of events 36,42 , and 53 are between 7.6 and 7.9 but estimates of $f_{M}$ for these events differ by a factor of 10 .

Since $f_{M}$ does not depend on magnitude, the stress drop $\Delta \tau$ increases with magnitude (Figure 3c, 3d). Poli and Prieto (2016) also observe an increase of $\Delta \tau$ with moment for 415 earthquakes deeper than $100 \mathrm{~km}$ by measuring total rupture durations from 
(a)
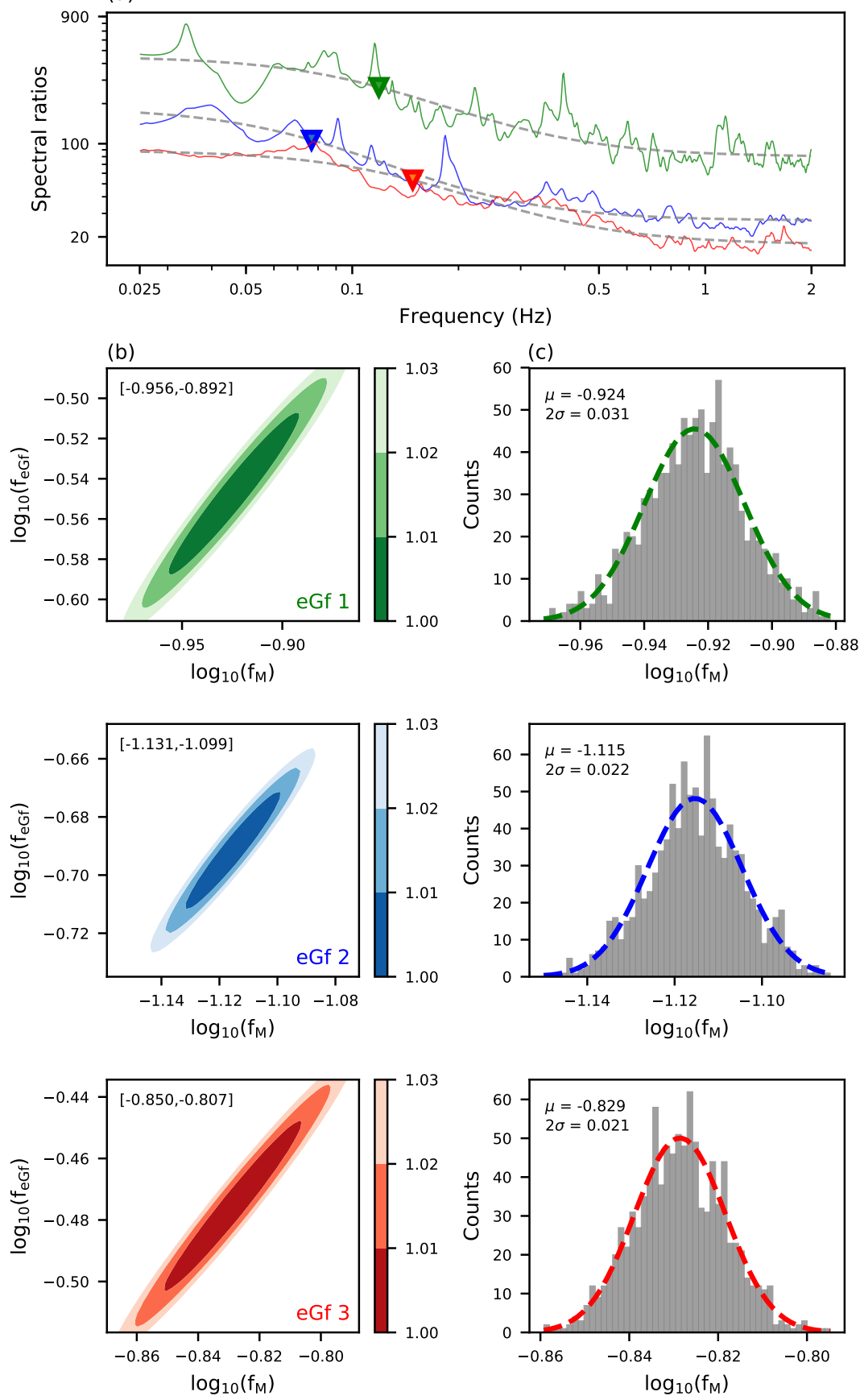

Figure 2. (a) Estimates of the S-wave spectral ratios (green, blue, and red solid lines) and corner frequencies (green, blue, and red triangles) of Event 5 (May 24, 2013; Sea of Okhotsk) based on three eGfs. The best-fit ratios are shown with dashed lines. (b) Contours of the misfit (scaled to minimum misfit) as a function of the corner frequencies of the master event (x-axis, $\log _{10}\left(f_{M}\right)$ and the eGf (y-axis, $\left.\log _{10}\left(f_{e G f}\right)\right)$ for the same three eGfs as in (a). Values in the upper left of each panel indicates the variation of $\log _{10}\left(f_{M}\right)$ for a misfit of 1.01. (c) Histograms of the estimated $\log _{10}\left(f_{M}\right)$ based on bootstrapping analysis. Dashed curves are best-fit Gaussians. Means $(\mu)$ and two-standard deviations $(2 \sigma)$ are indicated on the upper left of each panel. Note that spectral ratios and results of grid search and bootstrapping for the same eGf are depicted in the same color. 
source time functions. However, $f_{M}$ estimated in this study is affected more by the time at which the moment rate is highest than by the total rupture duration (Archuleta \& Ji, 2016). Furthermore, the increase of the stress drop in Figure 3c and 3d may be due to the narrow range of resolvable corner frequencies in our dataset. According to our spectral ratio analysis, several master events and corresponding eGfs in Figure S4 have similar seismic moments and therefore similar magnitudes, especially for P-wave results (Figure S3). Nevertheless, the ranges of $\mathrm{P}$-wave and $\mathrm{S}$-wave $\Delta \sigma$ are similar, and omitting these earthquake pairs does not change our interpretation (Figure S6). One-standard-deviation ranges of $\Delta \tau$ for $\mathrm{P}$ waves and $\mathrm{S}$ waves are $3.5-369.8 \mathrm{MPa}$ and $8.2-328.9 \mathrm{MPa}$, respectively. Their median values of 50.0 and $51.0 \mathrm{MPa}$ are higher than the estimate of 13.4 MPa from Poli and Prieto (2016). We do not observe a dependence of $\Delta \sigma$ on event depth and focal mechanism (Supplementary Figure S7 and S8 (Shearer et al., 2006)). Moreover, the earthquakes with the highest (event 42) and lowest (event 54) P-wave corner frequencies and stress drops have double-couple components smaller than $40 \%$. Since the Brune source model is based on shear failure of a planar fault, the corner frequencies of non-double-couple events may be poorly resolved.

In Figure 4 , we compare our P-wave estimates of $f_{M}$ and $\Delta \tau$ to the estimates from Allmann and Shearer (2009) who analyzed shallow $(<50 \mathrm{~km})$ earthquakes using teleseismic $\mathrm{P}$ waves and globally averaged empirical Green's functions. The highest value for $\Delta \tau$ in Allmann and Shearer (2009) is $1000 \mathrm{MPa}$. Assuming a Gaussian distribution, $95 \%$ of their stress drops are between 0.22 and $66 \mathrm{MPa}$ and have a median value of $4.0 \mathrm{MPa}$. Thus, Figure 4 suggests that the median stress drop of shallow earthquakes is 12.5 times smaller than the median stress drop of deep-focus earthquakes in the same magnitude range.

\section{Discussion}

Our study indicates that the stress drop of deep-focus earthquakes is higher than the stress drop of crustal earthquakes. This suggests that the mantle transition zone can accommodate shear faulting with higher stress drops. However, the difference in stress drop of shallow and deep-focus earthquakes may partly originate from the applied approaches. Shearer et al. (2019) compared the spectral ratio approach used in this study with the global eGf fitting approach used by Allmann and Shearer (2009). They found that, for the Brune source model, corner frequencies of a cluster of Landers aftershocks estimated using the spectral ratio approach are systematically higher than estimates using the global eGf fitting approach. However, it cannot explain the one-order-of-magnitude difference of median stress drops of shallow and deep-focus earthquakes shown (Figure 4 (c)). Moreover, assuming the Boatwright source model, the estimated corner frequencies have less scatter and there is better agreement between the two approaches.

The one-standard-deviation range of 3.5-369.8 MPa of the estimated stress drop (using $\mathrm{P}$ waves) implies that multiple physical mechanisms underlie deep-focus earthquake faulting. Shear-induced melting can accommodate shear failure with higher stress drops than phase transformation due to the large reduction of fault friction. The stress drop of the 1994 Mw8.3 Bolivia earthquake is estimated to be higher than $100 \mathrm{MPa}$ (e.g. Antolik et al., 1996; Kikuchi \& Kanamori, 1994) and faulting may have caused shearinduced melting (Kanamori et al., 1998; Zhan et al., 2014). In contrast, the 2013 Mw8.3 Sea of Okhotsk earthquake has a much smaller stress drop of 12-15 MPa (Ye et al., 2013) and may have been triggered by phase transformation (Zhan et al., 2014). Deep focus earthquakes may also involve a combination of shear melting and phase transformation (Meng et al., 2014; Zhan, 2017; Fan et al., 2019).

In our analysis, the source radius $r$ can be much smaller than the dimension of the rupture plane estimated from finite-fault inversions or back-projection studies because our estimate of the corner frequency is primarily sensitive to the area of the fault plane 

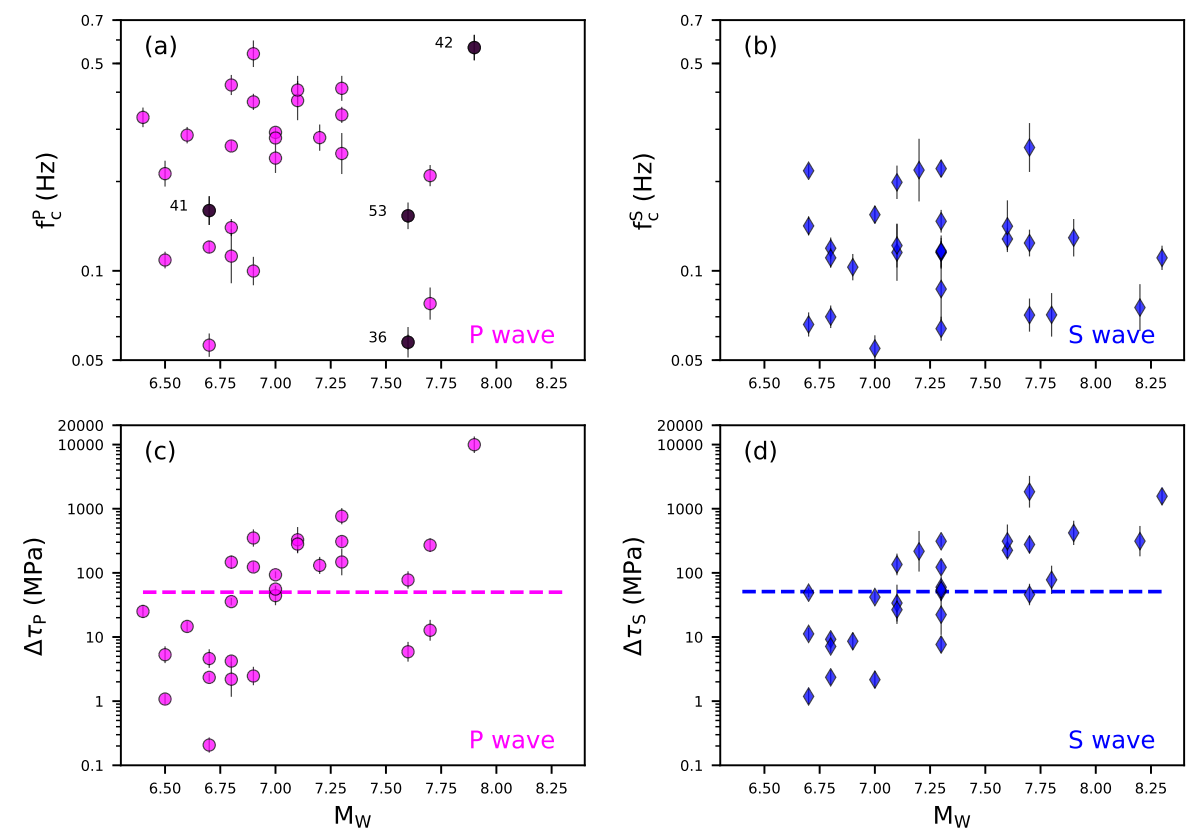

Figure 3. Corner frequencies ((a) and (b)) and stress drops ((c) and (d)) of master events as a function of moment magnitudes estimated from P-wave $((\mathrm{a})$ and $(\mathrm{c}))$ and S-wave $((\mathrm{b})$ and $(\mathrm{d}))$ spectra using Brune's source model. Vertical lines indicate $2 \sigma$ uncertainties determined by bootstrapping analysis. (a) Numbers to the left of four data points are the associated event numbers in Table 1. In (c) and (d), shaded areas are one-standard-deviation ranges of $\mathrm{P}$-wave (3.5-369.8 $\mathrm{MPa})$ and S-wave (8.2-328.9 $\mathrm{MPa}$ ) stress drop estimates; dashed lines in (c) and (d) indicate medians of $\mathrm{P}$-wave $(50.0 \mathrm{MPa})$ and $\mathrm{S}$-wave $(51.0 \mathrm{MPa})$ stress drops estimates.

(a)

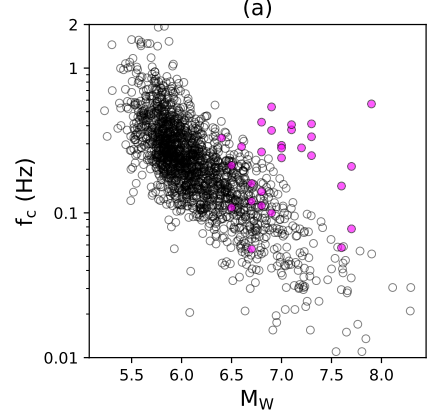

(b)

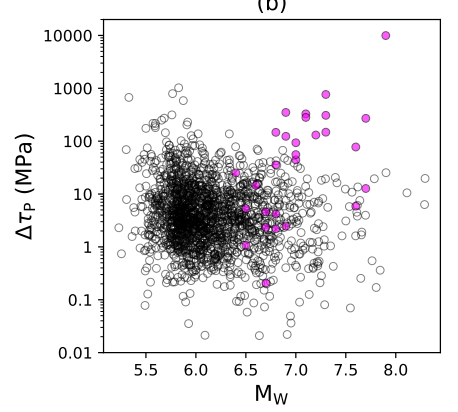

(c)

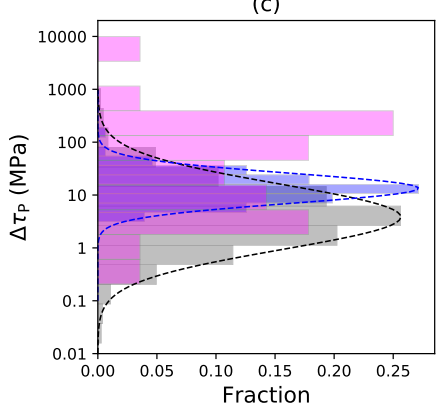

Figure 4. (a) Corner frequencies and (b) stress drops of shallow earthquakes (white circles) by (Allmann \& Shearer, 2009) and estimates for deep-focus earthquakes in this study (magenta circles). (c) Histograms of the stress drop distributions corresponding to data in (a) and (b). The blue histogram shows the stress-drop distribution of deep-focus earthquakes determined by Poli and Prieto (2016). Dashed lines are Gaussian contour fitting to histograms. The median stress drops of magenta, blue, and gray histograms are 50.0 MPa, 13.4 MPa, and 4.0 MPa. 
with highest slip. For example, we estimate that $r=9.4 \mathrm{~km}$ (i.e. rupture dimension of $278 \mathrm{~km}^{2}$ ) for the May 24, 2013 Sea of Okhotsk earthquake (Event 5 in Table 1). Although Ye et al. (2013) determined by kinematic slip inversion that the fault plane area was $180 \times 60 \mathrm{~km}^{2}$, our estimate of rupture dimension is consistent with the highest slip in Ye et al. (2013) $\left(\sim 600 \mathrm{~km}^{2}\right.$ for the $9.9 \mathrm{~m}$ slip contour in their Figure 1 and Figure S9 (a)) and in Zhan et al. (2014) $\left(\sim 314 \mathrm{~km}^{2}\right.$ for the $8.0 \mathrm{~m}$ slip contour in their Figure S3 (a)). Similarly, we estimate that the rupture area of the August 19, 2018 Fiji earthquake (Event 19 in Table 1) is $800 \mathrm{~km}^{2}(r=16.2 \mathrm{~km})$, which is 10 times smaller than $80 \times 100 \mathrm{~km}^{2}$ determined by Fan et al. (2019) from a back-projection analysis. Thus, stress drops interpreted in this study are primarily sensitive to the largest slip (Luco, 1985; Archuleta \& Ji, 2016), whereas finite fault inversions and back projection analyses resolve stress drops based on the overall dimension of the fault plane. Consequently, it is important to study stress drop variations using a consistent approach.

Our results suggest that the fault shear stress in the mantle transition zone is one order of magnitude higher than in the crust. This is significantly smaller than the two orders of magnitude difference of pressure in the crust and mantle (100s MPa versus 10s GPa). One explanation is high P-T experiments (e.g. Paola et al., 2015; H. Green et al., 2015) indicate that ground-boundary sliding may weaken faults if accompanied by phase transformation, with very low frictional resistance (H. Green et al., 2015) slightly depending on confining stress Tingle et al. (1993). In this case, shear failure can occur under shear stresses significantly smaller than static friction. Moreover, buoyancy forces caused by phase transformation that reach crustal shear stress Bina (1997); Yoshioka et al. (1997) or even higher level Goto et al. (1987) can trigger rupture of faults.

\section{Conclusion}

We measure the corner frequencies of global deep-focus earthquakes using the spectral ratio analysis based on teleseismic P-wave and S-wave spectra and a Brune source model. We find the one standard deviation ranges of $\mathrm{P}$-wave and $\mathrm{S}$-wave stress-drop estimates are $3.5-369.8 \mathrm{MPa}$ and $8.2-328.9 \mathrm{MPa}$, respectively. The median of the $\mathrm{P}$-wave and S-wave stress-drop estimates are 50.0 MPa and 51.0 MPa, respectively. These medians are about one order of magnitude higher than the median stress drop of global shallow earthquakes estimated by Allmann and Shearer (2009). The large variation of stress drops implies that both phase transformation and shear heating processes play important roles in the rupture processes of deep-focus earthquakes. Despite the two-ordersof-magnitude difference in the pressure in the mantle transition zone and crust, the comparison of median stress drops of shallow and deep-focus earthquakes suggests that the fault shear stress in the mantle is one order of magnitude higher than shear stresses in the crust.

\section{Acknowledgments}

This research was supported by National Science Foundation Grants EAR 1644829 to J. Ritsema and EAR 1943742 to Y. Huang. Y. Huang acknowledges the funding support from the University of Michigan. The IRIS Data Services and the IRIS Data Management Center provide the Global Seismographic Network (GSN) waveforms and related metadata used in this study. We thank Priero Poli for providing his catalog of stress drops of deep-focus earthquakes. We thank the editor (Gaven Hayes) and anonymous reviewers for helpful comments. Corner frequency and stress drop estimates are archived in the Deep Blue Data repository at https://doi.org/10.7302/sp05-y333. They are also archived in Table S1 in the Supporting Information. 


\section{References}

Abercrombie, R. E. (2015). Investigating uncertainties in empirical Green's function analysis of earthquake source parameters. Journal of Geophysical Research: Solid Earth, 120(6), 4263-4277.

Aki, K. (1967). Scaling law of seismic spectrum. Journal of geophysical research, 72(4), 1217-1231.

Aki, K. (1972). Earthquake mechanism. Tectonophysics, 13(1-4), 423-446.

Aki, K., \& Chouet, B. (1975). Origin of coda waves: source, attenuation, and scattering effects. Journal of geophysical research, 80(23), 3322-3342.

Allmann, B. P., \& Shearer, P. M. (2009). Global variations of stress drop for moderate to large earthquakes. Journal of Geophysical Research: Solid Earth, $114(\mathrm{~B} 1)$.

Antolik, M., Dreger, D., \& Romanowicz, B. (1996). Finite fault source study of the great 1994 deep Bolivia earthquake. Geophysical research letters, 23(13), 15891592.

Archuleta, R. J., \& Ji, C. (2016). Moment rate scaling for earthquakes $3.3 \leq \mathrm{M} \leq$ 5.3 with implications for stress drop. Geophysical Research Letters, 43(23), 12 004.

Bina, C. R. (1997). Patterns of deep seismicity reflect buoyancy stresses due to phase transitions. Geophysical research letters, 24(24), 3301-3304.

Boatwright, J. (1980). A spectral theory for circular seismic sources; simple estimates of source dimension, dynamic stress drop, and radiated seismic energy. Bulletin of the Seismological Society of America, 70(1), 1-27.

Branch, M. A., Coleman, T. F., \& Li, Y. (1999). A subspace, interior, and conjugate gradient method for large-scale bound-constrained minimization problems. SIAM Journal on Scientific Computing, 21(1), 1-23.

Brune, J. N. (1970). Tectonic stress and the spectra of seismic shear waves from earthquakes. Journal of geophysical research, 75 (26), 4997-5009.

Calderoni, G., Rovelli, A., Ben-Zion, Y., \& Di Giovambattista, R. (2015). Alongstrike rupture directivity of earthquakes of the 2009 L'Aquila, central italy, seismic sequence. Geophysical Journal International, 203(1), 399-415.

Campus, P., \& Das, S. (2000). Comparison of the rupture and radiation characteristics of intermediate and deep earthquakes. Journal of Geophysical Research: Solid Earth, 105(B3), 6177-6189.

Chen, Y., \& Wen, L. (2015). Global large deep-focus earthquakes: Source process and cascading failure of shear instability as a unified physical mechanism. Earth and Planetary Science Letters, 423, 134-144.

Chounet, A., Vallée, M., Causse, M., \& Courboulex, F. (2018). Global catalog of earthquake rupture velocities shows anticorrelation between stress drop and rupture velocity. Tectonophysics, 733, 148-158.

Dziewonski, A. M., \& Anderson, D. L. (1981). Preliminary reference Earth model. Physics of the earth and planetary interiors, 25(4), 297-356.

Eshelby, J. D. (1957). The determination of the elastic field of an ellipsoidal inclusion, and related problems. Proceedings of the Royal Society of London. Series A. Mathematical and Physical Sciences, 241(1226), 376-396.

Fan, W., Wei, S. S., Tian, D., McGuire, J. J., \& Wiens, D. A. (2019). Complex and Diverse Rupture Processes of the $2018 \mathrm{Mw} 8.2$ and Mw 7.9 Tonga-Fiji Deep Earthquakes. Geophysical Research Letters, 46(5), 2434-2448.

Frankel, A., \& Wennerberg, L. (1989). Microearthquake spectra from the Anza, California, seismic network: site response and source scaling. Bulletin of the Seismological Society of America, 79(3), 581-609.

Frohlich, C. (1989). The nature of deep-focus earthquakes. Annual Review of Earth and Planetary Sciences, 17(1), 227-254.

Goto, K., Suzuki, Z., \& Hamaguchi, H. (1987). Stress distribution due to olivinespinel phase transition in descending plate and deep focus earthquakes. Jour- 
nal of Geophysical Research: Solid Earth, 92(B13), 13811-13820.

Green, H., \& Burnley, P. (1989). A new self-organizing mechanism for deep-focus earthquakes. Nature, 341(6244), 733.

Green, H., Shi, F., Bozhilov, K., Xia, G., \& Reches, Z. (2015). Phase transformation and nanometric flow cause extreme weakening during fault slip. Nature Geoscience, 8(6), 484.

Green, H. W., \& Houston, H. (1995). The mechanics of deep earthquakes. Annual Review of Earth and Planetary Sciences, 23(1), 169-213.

Houston, H. (2015). 4.13 - Deep Earthquakes. In G. Schubert (Ed.), Treatise on geophysics (second edition) (Second Edition ed., p. 329 - 354). Oxford: Elsevier. doi: https://doi.org/10.1016/B978-0-444-53802-4.00079-8

Huang, Y., Beroza, G. C., \& Ellsworth, W. L. (2016). Stress drop estimates of potentially induced earthquakes in the Guy-Greenbrier sequence. Journal of Geophysical Research: Solid Earth, 121(9), 6597-6607.

Imanishi, K., \& Ellsworth, W. L. (2006). Source scaling relationships of microearthquakes at Parkfield, CA, determined using the SAFOD pilot hole seismic array. Earthquakes: Radiated Energy and the Physics of Faulting, 170, 81-90.

Kanamori, H., \& Anderson, D. L. (1975). Theoretical basis of some empirical relations in seismology. Bulletin of the seismological society of America, 65(5), 1073-1095.

Kanamori, H., Anderson, D. L., \& Heaton, T. H. (1998). Frictional melting during the rupture of the 1994 Bolivian earthquake. Science, 279(5352), 839-842.

Kanamori, H., \& Brodsky, E. E. (2004). The physics of earthquakes. Reports on Progress in Physics, 67(8), 1429.

Kaneko, Y., \& Shearer, P. (2014). Seismic source spectra and estimated stress drop derived from cohesive-zone models of circular subshear rupture. Geophysical Journal International, 197(2), 1002-1015.

Karato, S.-i., Riedel, M. R., \& Yuen, D. A. (2001). Rheological structure and deformation of subducted slabs in the mantle transition zone: implications for mantle circulation and deep earthquakes. Physics of the Earth and Planetary Interiors, 127(1-4), 83-108.

Kikuchi, M., \& Kanamori, H. (1994). The mechanism of the Deep Bolivia Earthquake of June 9, 1994. Geophysical Research Letters, 21(22), 2341-2344. doi: 10.1029/94GL02483

Kirby, S. H. (1987). Localized polymorphic phase transformations in high-pressure faults and applications to the physical mechanism of deep earthquakes. Journal of Geophysical Research: Solid Earth, 92(B13), 13789-13800.

Luco, J. E. (1985). On strong ground motion estimates based on models of the radiated spectrum. Bulletin of the Seismological Society of America, 75(3), 641649 .

Madariaga, R. (1976). Dynamics of an expanding circular fault. Bulletin of the Seismological Society of America, 66(3), 639-666.

Meng, L., Ampuero, J.-P., \& Bürgmann, R. (2014). The 2013 Okhotsk deep-focus earthquake: Rupture beyond the metastable olivine wedge and thermally controlled rise time near the edge of a slab. Geophysical Research Letters, 41(11), 3779-3785.

Mueller, C. S. (1985). Source pulse enhancement by deconvolution of an empirical Green's function. Geophysical Research Letters, 12(1), 33-36.

Paola, N. D., Holdsworth, R. E., Viti, C., Collettini, C., \& Bullock, R. $\quad$ (2015). Can grain size sensitive flow lubricate faults during the initial stages of earthquake propagation? Earth and Planetary Science Letters, 431, 48 - 58. doi: https://doi.org/10.1016/j.epsl.2015.09.002

Persh, S. E., \& Houston, H. (2004). Strongly depth-dependent aftershock production in deep earthquakes. Bulletin of the Seismological Society of America, 94(5), 
1808-1816.

Poli, P., \& Prieto, G. A. (2016). Global rupture parameters for deep and intermediate-depth earthquakes. Journal of Geophysical Research: Solid Earth, 121 (12), 8871-8887.

Ross, Z. E., \& Ben-Zion, Y. (2016). Toward reliable automated estimates of earthquake source properties from body wave spectra. Journal of Geophysical Research: Solid Earth, 121(6), 4390-4407.

Ruhl, C., Abercrombie, R., \& Smith, K. (2017). Spatiotemporal variation of stress drop during the 2008 Mogul, Nevada, earthquake swarm. Journal of Geophysical Research: Solid Earth, 122(10), 8163-8180.

Sato, T., \& Hirasawa, T. (1973). Body wave spectra from propagating shear cracks. Journal of Physics of the Earth, 21(4), 415-431.

Shearer, P. M., Abercrombie, R. E., Trugman, D. T., \& Wang, W. (2019). Comparing egf methods for estimating corner frequency and stress drop from $\mathrm{p}$ wave spectra. Journal of Geophysical Research: Solid Earth, 124(4), 3966-3986.

Shearer, P. M., Prieto, G. A., \& Hauksson, E. (2006). Comprehensive analysis of earthquake source spectra in southern California. Journal of Geophysical Research: Solid Earth, $111(\mathrm{~B} 6)$.

Tingle, T. N., Green, H. W., Scholz, C. H., \& Koczynski, T. (1993). The rheology of faults triggered by the olivine-spinel transformation in $\mathrm{Mg}_{2} \mathrm{GeO}_{4}$ and its implications for the mechanism of deep-focus earthquakes. Journal of Structural Geology, 15(9-10), 1249-1256.

Vallée, M. (2013). Source time function properties indicate a strain drop independent of earthquake depth and magnitude. Nature communications, 4, 2606.

Ye, L., Lay, T., Kanamori, H., \& Koper, K. D. (2013). Energy release of the 2013 Mw 8.3 Sea of Okhotsk earthquake and deep slab stress heterogeneity. Science, 341(6152), 1380-1384.

Yoshioka, S., Daessler, R., \& Yuen, D. A. (1997). Stress fields associated with metastable phase transitions in descending slabs and deep-focus earthquakes. Physics of the earth and planetary interiors, 104 (4), 345-361.

Zhan, Z. (2017). Gutenberg-Richter law for deep earthquakes revisited: A dualmechanism hypothesis. Earth and Planetary Science Letters, 461, 1-7.

Zhan, Z., Kanamori, H., Tsai, V. C., Helmberger, D. V., \& Wei, S. Rupture complexity of the 1994 Bolivia and 2013 Sea of Okhotsk deep earthquakes. $\quad$ Earth and Planetary Science Letters, 385, 89 - $96 . \quad$ doi: https://doi.org/10.1016/j.epsl.2013.10.028

Zhan, Z., Shearer, P. M., \& Kanamori, H. (2015). Supershear rupture in the 24 May 2013 Mw 6.7 Okhotsk deep earthquake: Additional evidence from regional seismic stations. Geophysical Research Letters, 42(19), 7941-7948. 